\title{
Effects of Sulfur and Titanium Interaction in Molten Pig Iron on Erosion of Carbon Brick
}

\author{
Yong DENG, ${ }^{1,2)}$ Jianliang ZHANG, ${ }^{1,2)}$ Kexin $\mathrm{JIAO}^{1,2)}$ and Zhengjian LIU ${ }^{1,2) *}$ \\ 1) School of Metallurgical and Ecological Engineering, University of Science and Technology Beijing, Beijing, 100083 China. \\ 2) State Key Laboratory of Advanced Metallurgy, University of Science and Technology Beijing, Beijing, 100083 China.
}

(Received on July 3, 2018; accepted on September 4, 2018; J-STAGE Advance published date: September 22, 2018)

\begin{abstract}
The service life of blast furnace is largely determined by the erosion of carbon brick. The experiments were carried out to investigate effects of sulfur and titanium interaction in molten pig iron on erosion of carbon brick. The experimental results show that the erosion of carbon brick was enhanced when the sulfur content increased separately in molten pig iron, however, this effect could be made up by addition of titanium in molten pig iron. The control standard of sulfur content and titanium content in molten pig iron was proposed, which was combined with the operation to delay the erosion of carbon brick. The quantitative relationship between the erosion rate and sulfur and titanium interaction at $1773 \mathrm{~K}$ was obtained based on experimental data, when sulfur content increased by $0.01 \%$, the increment of titanium content by $0.015 \%$ would be needed to compensate for the effect of sulfur content on the erosion. The mechanism of sulfur and titanium interaction was analyzed through the erosion process of carbon brick, the difference between the influences of two elements on the surface tension and viscosity of molten is the essential cause of the interaction.
\end{abstract}

KEY WORDS: blast furnace; carbon brick erosion; sulfur and titanium interaction; quantitative relationship; mechanism.

\section{Introduction}

The service life of blast furnace (BF) is largely determined by the erosion of carbon brick, ${ }^{1,2}$ the erosion is inevitable due to the direct contact between carbon-undersaturated molten pig iron and carbon brick. ${ }^{3,4)}$ The erosion rate is affected by temperature, element content, the flow of molten pig iron et al., ${ }^{5)}$ to reduce the erosion rate of carbon brick has become the primary target to prolong the service life of $\mathrm{BF}$.

Sulfur is a harmful element in molten pig iron. ${ }^{6)}$ It is not economical to conduct a deep desulphurization in $\mathrm{BF}$ although the desulphurization (working) conditions of $\mathrm{BF}$ becomes better. ${ }^{7-9)}$ With the development of desulphurization in pretreatment of molten pig iron, sulfur in molten pig iron can be removed to less than $0.01 \%$ in a short time due to good thermodynamic and kinetic conditions for desulphurization. It has become a trend of most BFs to rely on external desulphurization to reduce cost. ${ }^{10-14)}$ Therefore, sulfur content in molten pig iron is gradually improved, and the erosion rate of carbon brick in hearth is affected by this change. On the other hand, raw materials containing titania charged in $\mathrm{BF}$ is an effective measure to protect the hearth at the end of the service. ${ }^{15-18)}$ The titania in iron ore is reduced to form titanium and the titanium is dissolved into molten

\footnotetext{
* Corresponding author: E-mail: liuzhengjian@126.com DOI: https://doi.org/10.2355/isijinternational.ISIJINT-2018-467
}

pig iron. The titanium content increases in molten pig iron, and at this moment, the surface of carbon brick will be faced with the molten pig iron with high sulfur content and high titanium content in hearth. ${ }^{19,20)}$ In spite of some investigations on molten pig iron containing sulfur or molten pig iron containing titanium, less effort has been paid to effects of sulfur and titanium interaction in molten pig iron on erosion of carbon brick. Moreover, the quantitative relationship between the erosion rate and element content has not been known, the mechanism of sulfur and titanium interaction has not been clarified.

The experiments were carried out to investigate effects of sulfur and titanium interaction in molten pig iron on erosion of carbon brick in this paper, the quantitative relationship between the erosion rate and sulfur and titanium interaction was regressed by origin. A discussion was done to explain the mechanism of sulfur and titanium interaction in molten pig iron.

\section{Experimental}

\subsection{Samples Preparation}

A mixture of reduced iron powder and other powders were used to melt into molten pig iron. The mass of required powders was precisely weighed by a balance according to the mass percentage of each element as presented in Table 1. The experimental ambient temperature was set to 1773 $\mathrm{K}$ which was close to the actual temperature of BF hearth. 
Table 1. Experimental conditions for sulfur and titanium interaction.

\begin{tabular}{cccccccccc}
\hline Number & T, K & $\begin{array}{c}\text { Agitation, } \\
\text { rpm }\end{array}$ & $\begin{array}{c}\text { Fe, } \\
\%\end{array}$ & $\begin{array}{c}\mathrm{C}, \\
\%\end{array}$ & $\begin{array}{c}\mathrm{Si}, \\
\%\end{array}$ & $\begin{array}{c}\mathrm{Mn}, \\
\%\end{array}$ & $\begin{array}{c}\mathrm{P}, \\
\%\end{array}$ & $\begin{array}{c}\mathrm{S}, \\
\%\end{array}$ & $\begin{array}{c}\mathrm{Ti}, \\
\%\end{array}$ \\
\hline J-1 & 1773 & 200 & 94.63 & 4.5 & 0.4 & 0.3 & 0.1 & 0.02 & 0.05 \\
$\mathrm{~J}-2$ & 1773 & 200 & 94.58 & 4.5 & 0.4 & 0.3 & 0.1 & 0.02 & 0.10 \\
J-3 & 1773 & 200 & 94.53 & 4.5 & 0.4 & 0.3 & 0.1 & 0.02 & 0.15 \\
K-1 & 1773 & 200 & 94.61 & 4.5 & 0.4 & 0.3 & 0.1 & 0.04 & 0.05 \\
K-2 & 1773 & 200 & 94.56 & 4.5 & 0.4 & 0.3 & 0.1 & 0.04 & 0.10 \\
K-3 & 1773 & 200 & 94.51 & 4.5 & 0.4 & 0.3 & 0.1 & 0.04 & 0.15 \\
L-1 & 1773 & 200 & 94.59 & 4.5 & 0.4 & 0.3 & 0.1 & 0.06 & 0.05 \\
L-2 & 1773 & 200 & 94.54 & 4.5 & 0.4 & 0.3 & 0.1 & 0.06 & 0.10 \\
L-3 & 1773 & 200 & 94.49 & 4.5 & 0.4 & 0.3 & 0.1 & 0.06 & 0.15 \\
M-1 & 1773 & 200 & 94.57 & 4.5 & 0.4 & 0.3 & 0.1 & 0.08 & 0.05 \\
M-2 & 1773 & 200 & 94.52 & 4.5 & 0.4 & 0.3 & 0.1 & 0.08 & 0.10 \\
M-3 & 1773 & 200 & 94.47 & 4.5 & 0.4 & 0.3 & 0.1 & 0.08 & 0.15 \\
\hline
\end{tabular}

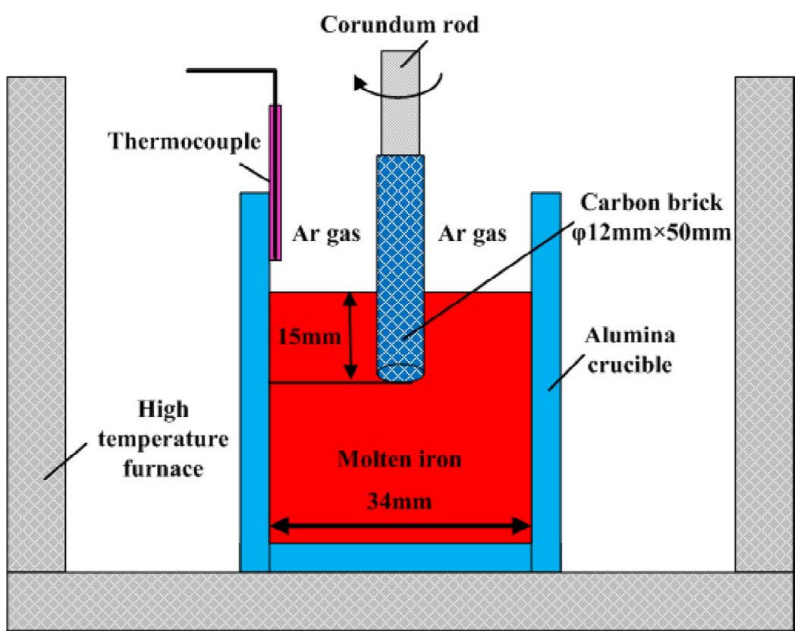

Fig. 1. Schematic diagram of experimental apparatus. (Online version in color.)
The saturated carbon content in molten pig iron was about $5.0 \%$ according to the calculation, so carbon content in molten pig iron was undersaturated under the conditions of the experimental temperature and the composition of molten pig iron. The powders which were mixed uniformity were packed into an alumina crucible. The carbon brick lined on the hearth in a large commercial BF was selected as experimental sample, it was cut into cylindrical specimens to carry out experiments. The main chemical composition of the carbon brick was analyzed to be $\mathrm{C}(82.30 \%), \mathrm{SiO}_{2}$ $(8.75 \%)$ and $\mathrm{Al}_{2} \mathrm{O}_{3}(2.10 \%)$.

\subsection{Experimental Procedure}

The rotating cylinder method was employed to simulate the erosion of carbon brick in hearth. The cylindrical specimen was immersed in molten pig iron as presented in Fig. 1, when the high temperature tube furnace reached the desired temperature. The motor which was connected with the cylindrical specimen drove the cylindrical specimen so as to carry out experiments and persistent for 60 minutes. After the rotation, the cylindrical specimen was quenched quickly and moulded in epoxy for SEM (Scanning Electron Microscope) and EDS (Energy Dispersive Spectrometer), the diameter of the cylindrical specimen was measured to calculate the erosion rate of carbon brick.

\section{Experimental Results}

The diameter of carbon brick before and after the experiment was measured. The zone of carbon brick which was immersed in molten pig iron was selected to measure the diameter. The circumferential erosion uniform region of carbon brick was measured to avoid the error caused by convex and concave. The measurement at the part was carried out three times by using a vernier caliper at every 5 $\mathrm{mm}$ from the bottom of carbon brick, the average value of
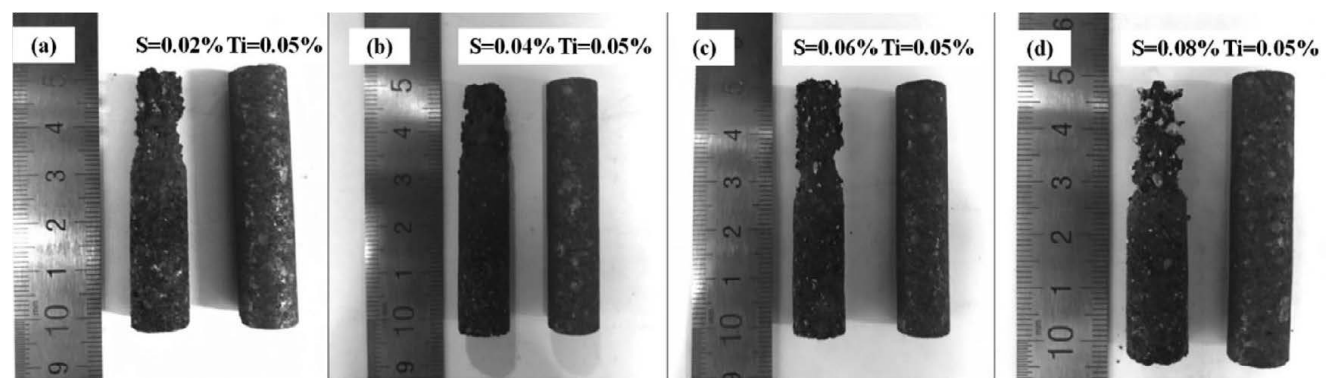

Fig. 2. Effect of sulfur content on the erosion.
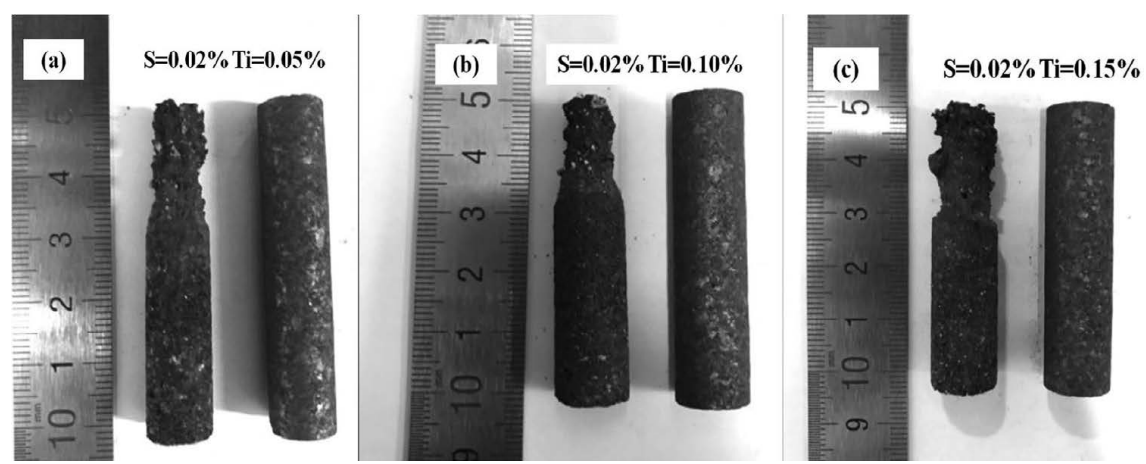

Fig. 3. Effect of titanium content on the erosion. 
Table 2. The erosion rate of carbon brick.

\begin{tabular}{cccc}
\hline Composition & $d_{f}, \mathrm{~mm}$ & $\Delta d, \mathrm{~mm} \cdot \mathrm{h}^{-1}$ & $v, \mathrm{~g} \cdot \mathrm{h}^{-1} \cdot \mathrm{cm}^{-2}$ \\
\hline$[\mathrm{S}]=0.02 \%[\mathrm{Ti}]=0.05 \%$ & 10.78 & 1.22 & 0.069 \\
{$[\mathrm{~S}]=0.02 \%[\mathrm{Ti}]=0.10 \%$} & 11.20 & 0.80 & 0.046 \\
{$[\mathrm{~S}]=0.02 \%[\mathrm{Ti}]=0.15 \%$} & 11.50 & 0.50 & 0.029 \\
{$[\mathrm{~S}]=0.04 \%[\mathrm{Ti}]=0.05 \%$} & 10.36 & 1.64 & 0.091 \\
{$[\mathrm{~S}]=0.04 \%[\mathrm{Ti}]=0.10 \%$} & 11.04 & 0.96 & 0.055 \\
{$[\mathrm{~S}]=0.04 \%[\mathrm{Ti}]=0.15 \%$} & 11.42 & 0.58 & 0.034 \\
{$[\mathrm{~S}]=0.06 \%[\mathrm{Ti}]=0.05 \%$} & 10.28 & 1.72 & 0.095 \\
{$[\mathrm{~S}]=0.06 \%[\mathrm{Ti}]=0.10 \%$} & 10.56 & 1.44 & 0.081 \\
{$[\mathrm{~S}]=0.06 \%[\mathrm{Ti}]=0.15 \%$} & 11.20 & 0.80 & 0.046 \\
{$[\mathrm{~S}]=0.08 \%[\mathrm{Ti}]=0.05 \%$} & 10.12 & 1.88 & 0.103 \\
{$[\mathrm{~S}]=0.08 \%[\mathrm{Ti}]=0.10 \%$} & 10.20 & 1.80 & 0.099 \\
{$[\mathrm{~S}]=0.08 \%[\mathrm{Ti}]=0.15 \%$} & 10.80 & 1.20 & 0.068 \\
\hline
\end{tabular}

the three measurements was taken as the diameter after the experiment.

\subsection{Erosion Morphology}

The photographs of carbon bricks after the experiment are presented in Figs. 2 and 3. At the erosion zone, a decrease of diameter was observed. Meanwhile, the degree of erosion was related with the element content. The erosion of carbon brick was enhanced when sulfur content increased separately in molten pig iron, and the erosion was delayed when titanium content increased separately in molten pig iron.

\subsection{Erosion Rate of Carbon Brick}

The erosion rate of carbon brick was defined as: ${ }^{21)}$

$$
v=\frac{\pi \times l \times\left(d_{0}^{2}-d_{f}^{2}\right) \times \rho \times w_{C}}{4 \times t \times s}
$$

where $v$ is the erosion rate of carbon brick, $\mathrm{g} \cdot \mathrm{h}^{-1} \cdot \mathrm{cm}^{-2}$; $l$ is the immersion depth of carbon brick into the molten pig iron, $\mathrm{cm} ; d_{0}$ is the diameter of carbon brick before the experiment, $\mathrm{cm} ; d_{f}$ is the diameter of carbon brick after the experiment, $\mathrm{cm} ; \rho$ is the density of carbon brick, $\mathrm{g} \cdot \mathrm{cm}^{-3}$; $w_{C}$ is the carbon content of the carbon brick, $82.3 \%$; $t$ is reaction time, $\mathrm{h} ; s$ is reaction area, $\mathrm{cm}^{2}$, the change of the reaction area with the passage of time can be ignored due to the relatively small change in the diameter compared to the initial diameter.

The erosion rate of carbon brick is shown in Table 2 .

\section{Discussion}

\subsection{Sulfur and Titanium Interaction}

Effects of sulfur and titanium interaction on the erosion rate are presented in Fig. 4. The situation that sulfur content is $0.08 \%$ without titanium in molten pig iron which shows the highest erosion rate is displayed at the top, and the case that molten pig iron without sulfur which shows the lowest erosion rate is displayed at the bottom. The middle part of Fig. 4 shows sulfur and titanium interaction.

The relationship between sulfur content and the erosion rate at $[\mathrm{Ti}]=0.10 \%$ which is marked with a red line in Fig. 4 is presented in Fig. 5, it is concluded from Fig. 5, the ero-

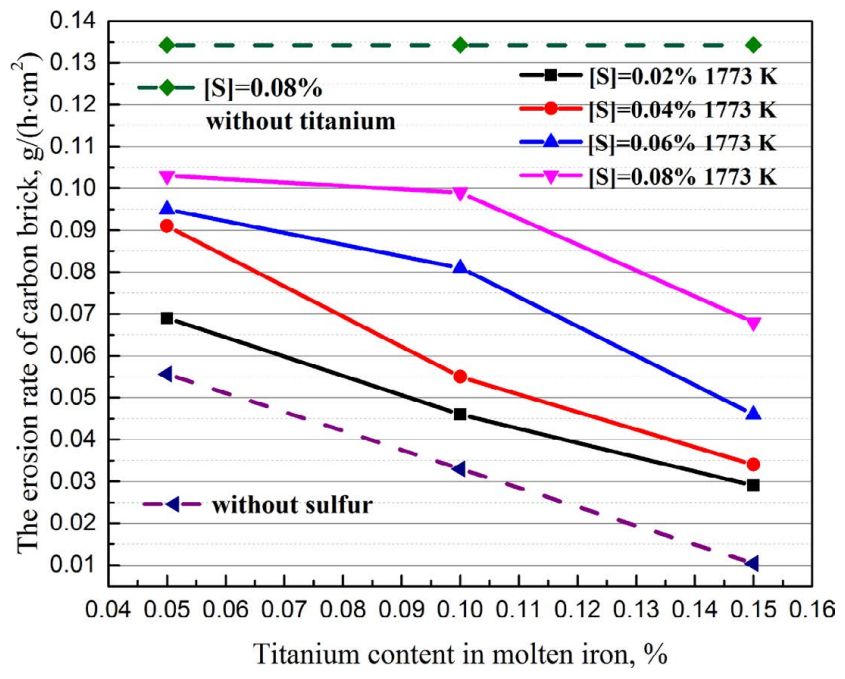

Fig. 4. Effects of sulfur and titanium interaction on the erosion rate. (Online version in color.)

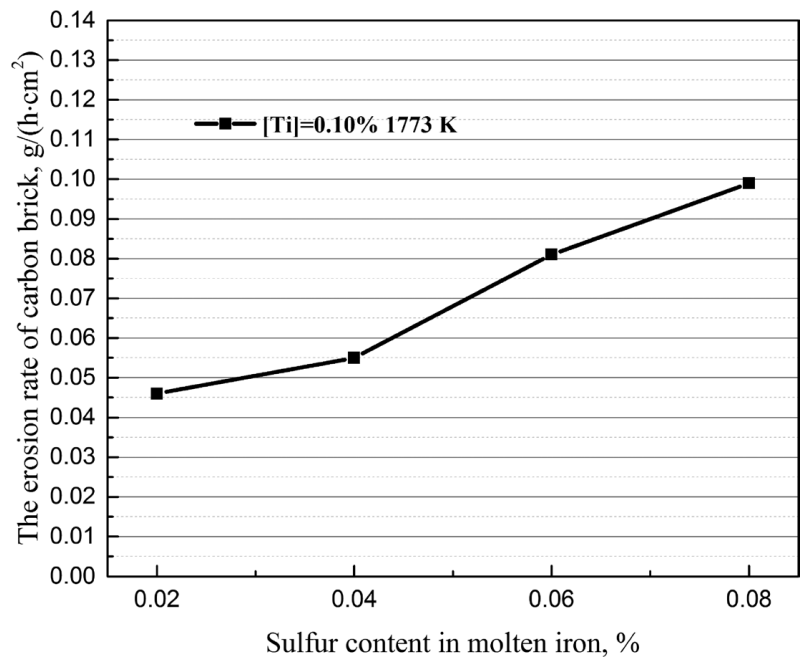

Fig. 5. The relationship between sulfur content and the erosion rate at $[\mathrm{Ti}]=0.10 \%$.

sion rate of carbon brick was enhanced when sulfur content increased separately in molten pig iron. The erosion rate increased slowly when sulfur content was less than $0.04 \%$, however, the erosion rate increased rapidly when sulfur content was more than $0.04 \%$, because the slope of the straight line became larger. Therefore, it is suggested that the sulfur content of molten pig iron should be controlled less than $0.04 \%$ in actual production.

On the other hand, as presented in Fig. 4, when sulfur content in molten pig iron remained stable, the erosion rate decreased with the increase of titanium content, but there was a difference in the degree of decline. The erosion rate was relatively high when titanium content was $0.05 \%$. The erosion rate was still $0.068 \mathrm{~g} \cdot \mathrm{h}^{-1} \cdot \mathrm{cm}^{-2}$ at most although sulfur content in molten pig iron was $0.02 \%$. It was no obvious protective effect on carbon brick when titanium content was low. A decrease of erosion rate was observed when titanium content remained $0.10 \%$, but the effect was significant for low sulfur content in molten pig iron (less than 0.04\%), not obvious for high sulfur content in molten pig iron (more than $0.06 \%$ ). Thus, it is suggested that titanium content in molten pig iron should be controlled more than $0.10 \%$ in the 
protection process of hearth. The sharp decline of erosion rate was observed even for high sulfur content in molten pig iron (more than $0.06 \%$ ) when titanium content rose up to $0.10 \%$. The erosion rate at $0.08 \%$ of sulfur content and $0.15 \%$ of titanium content was lower than that at $0.06 \%$ of sulfur content and $0.10 \%$ of titanium content, which indicated that the high titanium content could effectively compensate for the effect of high sulfur content in molten pig iron on the erosion.

The quantitative relationship between the erosion rate and sulfur and titanium interaction at $1773 \mathrm{~K}$ was obtained based on regression analysis of all experimental data by origin:

$$
v=0.07825+0.7[S]-0.4525[T i]
$$

Equation (2) expresses the erosion rate would change with sulfur and titanium interaction in molten pig iron. The erosion rate would increase $0.007 \mathrm{~g} \cdot \mathrm{h}^{-1} \cdot \mathrm{cm}^{-2}$ when sulfur content increased by $0.01 \%$, and the erosion rate would decrease $0.004525 \mathrm{~g} \cdot \mathrm{h}^{-1} \cdot \mathrm{cm}^{-2}$ when titanium content increased by $0.01 \%$. In other words, when sulfur content increased by $0.01 \%$, the titanium content needed to be increased by $0.015 \%$ to compensate for the effect of sulfur content on the erosion of carbon brick.

\subsection{The Erosion Process of Carbon Brick}

The penetration and dissolution of molten pig iron are considered as the main reasons for the erosion of carbon brick. The micro morphology of carbon brick under different sulfur content is shown in Fig. 6. As you can see from the figure, the reaction interface was smooth when sulfur content was low, the attachment of iron bead to the reaction interface appeared with the increase of sulfur content. The penetration and dissolution were conducted alternately in the erosion, when the penetration was faster, the iron and carbon particles had not been dissolved into molten pig iron yet, then appeared at the interface. Therefore, the penetration rate increased because the fluidity of molten pig iron was improved at higher sulfur content in molten pig iron.

The erosion process of carbon brick can be inferred from Fig. 7 after the erosion. The erosion of carbon brick would take place when the iron-carbon interface was produced by the contact of molten pig iron and carbon brick as shown in Fig. 7(a). Then, the penetration of molten pig iron would occur through the micropore of carbon brick and the main route of the penetration was formed due to the high temperature and the low viscosity of molten pig iron (Fig. 7(b)). Molten pig iron in the main channel would continue to penetrate into the surrounding pores along the inner carbon brick, and the dendrimer permeation was found. The dissolution of carbon brick would occur at the interface because the carbon was surrounded by the molten pig iron which is undersaturated (Fig. 7(c)). The new iron-carbon interface would be re exposed in molten pig iron after a layer of carbon brick was dissolved off. The erosion process of carbon brick can be presumed as follows: (1) The penetration of molten pig iron will occur through the micropore of carbon brick; (2) The dissolution of carbon brick will occur because the carbon content of molten pig iron is undersaturated; (3) The penetration and dissolution will be conducted alternately; (4) The iron-carbon interface will move into the inner part of carbon brick, so that the erosion is irreversible.
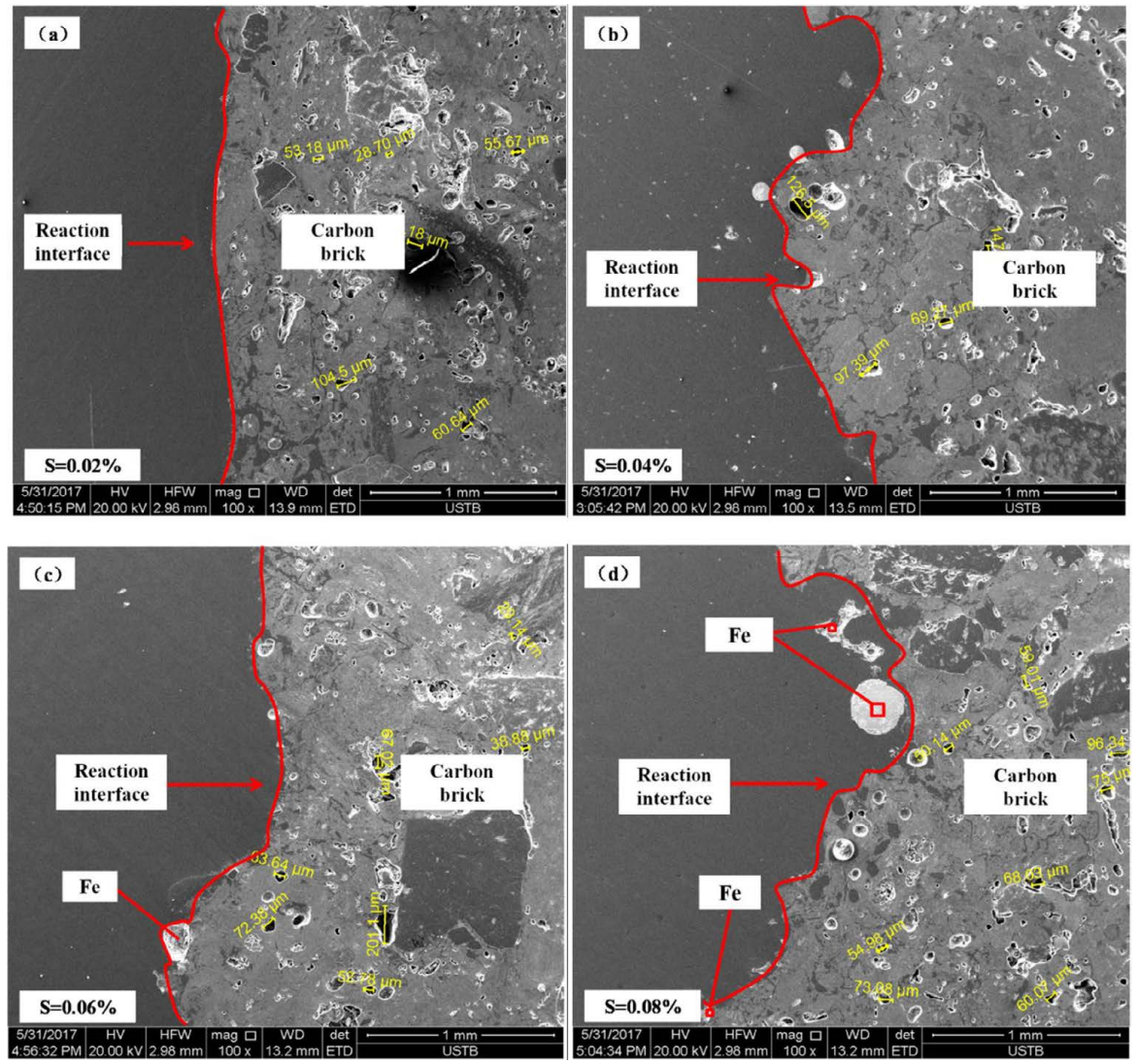

Fig. 6. The micro morphology of carbon brick under different sulfur content. (Online version in color.) 

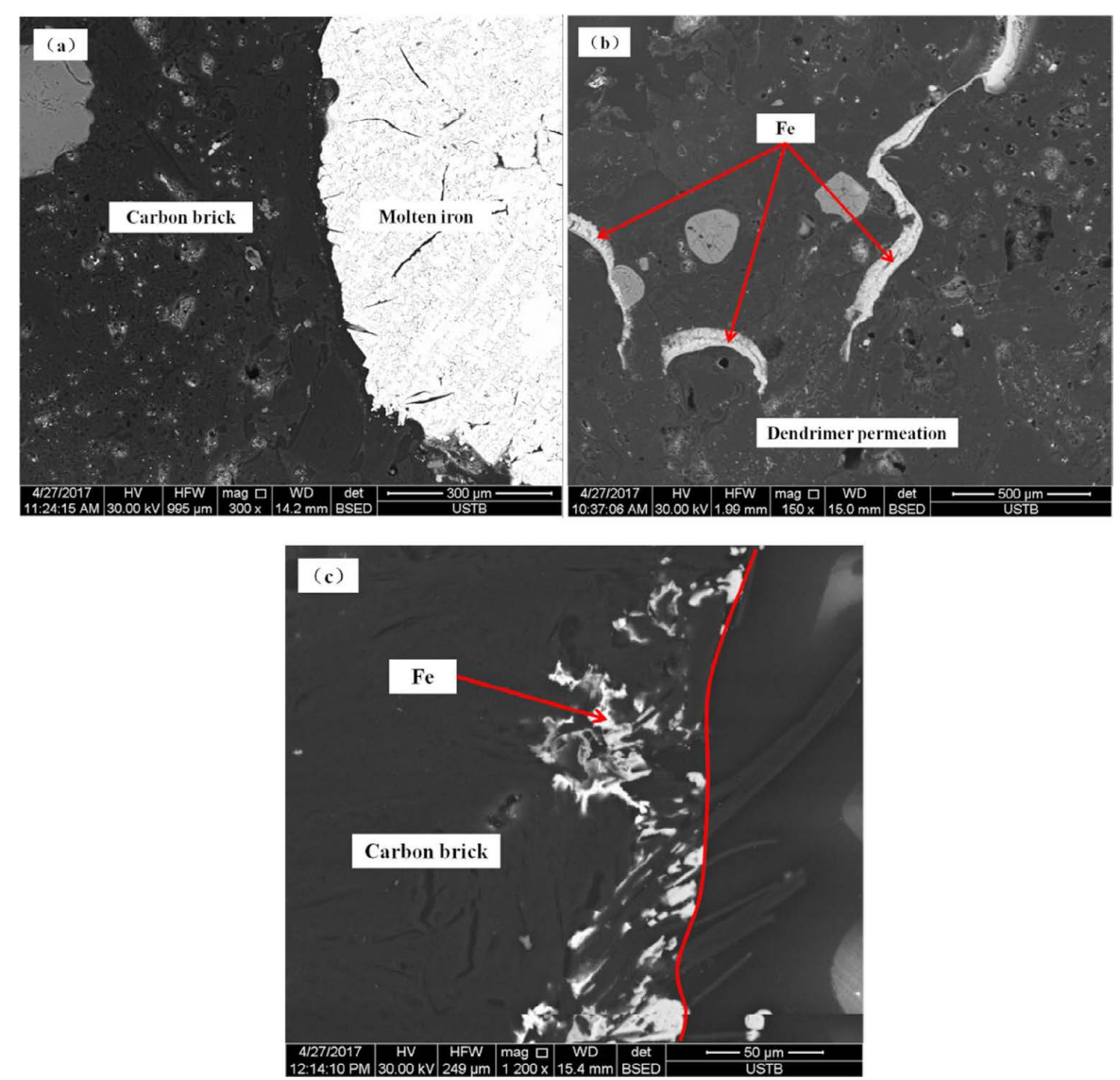

Fig. 7. The erosion process of carbon brick. (Online version in color.)

\subsection{The Mechanism of Sulfur and Titanium Interac- tion}

On one hand, sulfur and titanium interaction may affect the erosion rate from the point of thermodynamics. On the other hand, the iron-carbon interface will be updated continually in the erosion process of carbon brick. The good wettability between molten pig iron and carbon will result in the quickly contact with the new interface and carbon will continue to react with molten pig iron so as to increase the erosion rate. On the contrary, the bad wettability will extend the contact time of molten pig iron at the new interface, which will make the reduction of the erosion rate. Therefore, sulfur and titanium interaction could be related with the wettability of the iron-carbon interface.

\subsubsection{Thermodynamic Analysis}

The total dissolution reaction of carbon brick can be expressed as: ${ }^{22)}$

$$
C=[C] \Delta G^{0}=22590-42.26 T \mathrm{~kJ} / \mathrm{mol}
$$

when the reaction reaches the thermodynamic equilibrium:

$$
\Delta G^{0}=-R T \ln K=-2.303 R T \log K
$$

for the equilibrium constant:

$$
\log K=\log \frac{a_{C}}{a_{\text {solid }}}=\log a_{C}=\log [\% C]+\log f_{C} \ldots
$$

Activity of solid carbon can be assumed to be unit, the following equation can be obtained:

$$
\log [\% C]=-\frac{1179.81}{T}+2.21-\log f_{C}
$$

for sulfur and titanium interaction in molten pig iron according to the Wagner model ${ }^{23)}$ in metallurgical thermodynamics:

$$
\log f_{C}=e_{C}^{C}[\% C]+e_{C}^{S}[\% S]+e_{C}^{T i}[\% T i]
$$

Equation (8) can be obtained from above equations:

$$
\log [\% C]=-\frac{1179.81}{T}+2.21-e_{C}^{C}[\% C]-e_{C}^{S}[\% S]-e_{C}^{T i}[\% T i]
$$

where $T$ is the temperature, $\mathrm{K} ; e_{C}^{j}$ is the interaction coefficient of $j$ element to carbon, $e_{C}^{C} e_{C}^{S} e_{C}^{T i}$ are $0.14,0.016$, -0.041 , respectively, at $1873 \mathrm{~K}$ according to reference. ${ }^{22}$ ) The interaction coefficients at different temperatures can be calculated:

$$
e_{T}=e \times 1873 / T
$$

where $e_{T}$ is the interaction coefficient at temperature $T$.

The mass of carbon dissolution is related to element content and interaction coefficient. The difference between $e_{C}^{S}$ and $e_{C}^{T i}$ shows different effects of sulfur and titanium on dissolution. Relationship between apparent equilibrium carbon content in molten pig iron and sulfur content or titanium content are calculated by the above equations in Fig. 8, When the sulfur content increased, apparent equilibrium carbon content slightly decreased. On the contrary, when the titanium content increased, apparent equilibrium carbon content slightly increased. However, the magnitude of the 

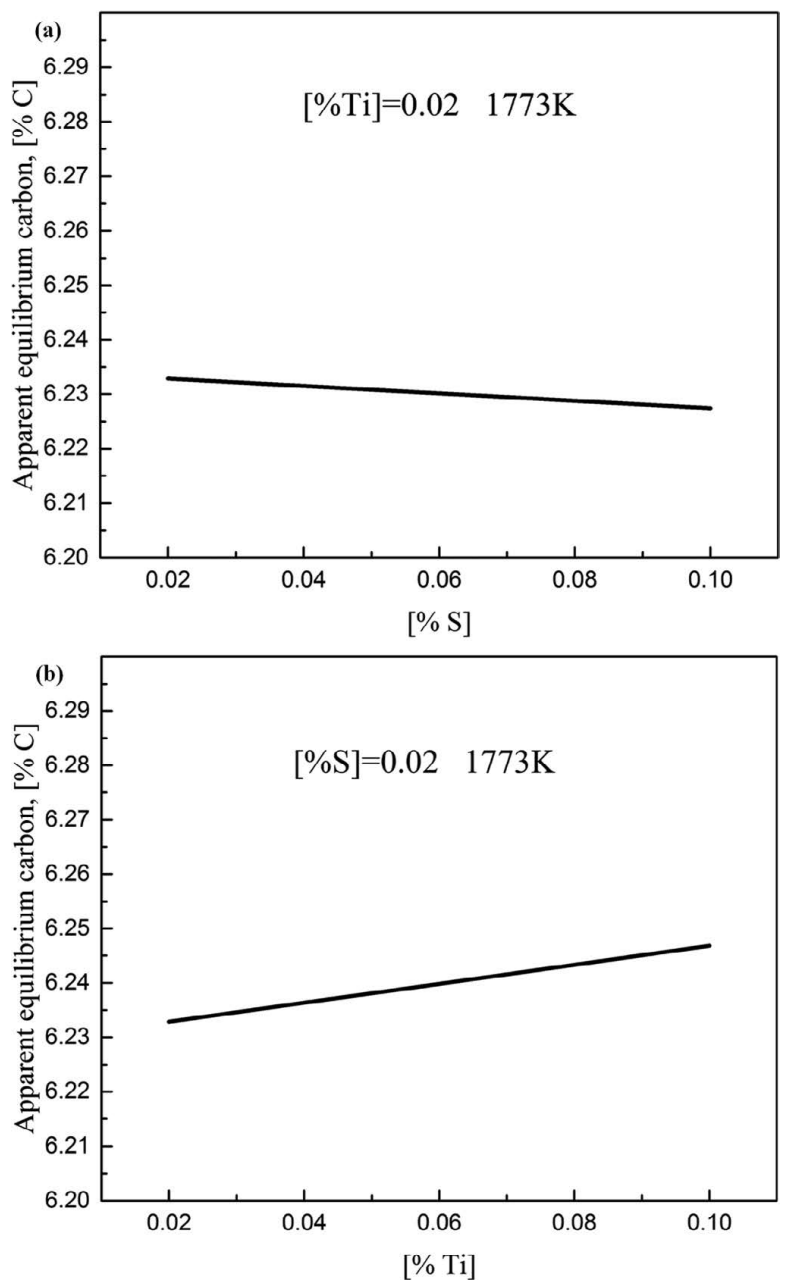

Fig. 8. Relationship between apparent equilibrium carbon and sulfur, titanium content.

increment looked very small. The actual observed phenomena were reversed and these were quite different from thermodynamic calculation. As a result, these phenomena could not be explained by using thermodynamics. Therefore, we tried to discuss the mechanism of erosion by focusing on the change of physical properties such as surface tension and viscosity.

\subsubsection{Surface Tension}

The surface tension of molten melt refers to the tension between any two adjacent parts of the liquid surface perpendicular to the boundary of their unit length. ${ }^{24)}$ The composition and temperature of molten melt are two important factors affecting the surface tension.

About the surface tension of molten pig iron, the degree of difference between the element and the iron atom in molten pig iron determines the extent of its influence on the surface tension of molten pig iron. If the properties of the element in molten pig iron are similar to iron atom, the interaction force between element atom and iron atom is similar to that between iron atoms, and this element has little influence on the surface tension of molten pig iron. ${ }^{25)}$ On the contrary, the element has great influence on the surface tension of molten pig iron. The influence of metal elements on the surface tension of molten pig iron is small, but nonmetallic elements have a great influence on the surface tension of molten pig iron.

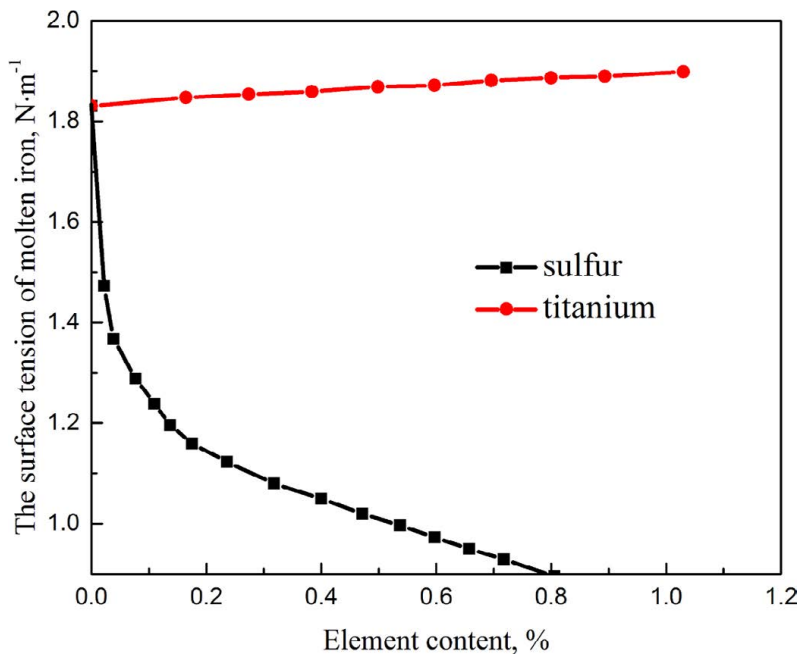

Fig. 9. Effects of sulfur and titanium on the surface tension. (Online version in color.)

Effects of sulfur and titanium on the surface tension of molten pig iron with element content are presented in Fig. 9. It can be concluded from the figure that titanium is a metal element which had little influence on the surface tension of molten pig iron, the surface tension of molten pig iron increased slightly with the increase of titanium content. However, sulfur is a strong surface active element which had a great influence on the surface tension of molten pig iron, the surface tension of molten pig iron dropped sharply with the increase of sulfur content in molten pig iron. The large difference between the influences of two elements on the surface tension of molten pig iron may be a reason for the interaction.

Surface tension of molten pig iron affects the reaction through wetting angle. The wetting angle reflects the wettability between molten pig iron and carbon brick, the smaller wetting angle reflects the better wettability. The wetting angle is related with the interfacial tension between the gas and carbon brick, the interfacial tension between molten pig iron and carbon brick and the surface tension of molten pig iron. Yang's equation is employed to describe the relationship among the three forces: ${ }^{26}$

$$
\gamma_{s g}-\gamma_{s l}=\gamma \cos \theta
$$

where $\theta$ is the wetting angle, ${ }^{\circ} ; \gamma_{s g}, \gamma_{s l}, \gamma$ are the interfacial tension between the gas and carbon brick, the interfacial tension between molten pig iron and carbon brick and the surface tension of molten pig iron, respectively, $\left(\mathrm{N} \cdot \mathrm{m}^{-1}\right)$.

As shown in Eq. (10), $\gamma \cos \theta$ will be a fixed value when other factors don't change, so the wetting angle will decrease with the decrease of surface tension. Thus, for molten pig iron containing titanium, the increase of sulfur led to the rapid decrease of the surface tension so as to decrease the wetting angle. The better wettability between molten pig iron and carbon will result in the quickly contact with the new interface. And carbon will continue to dissolve into molten pig iron so that the erosion rate will increase. Furthermore, the erosion rate was enhanced owing to the decrease of viscosity of molten pig iron by the addition of sulfur. 


\subsubsection{Viscosity}

The viscosity of molten pig iron has been thought to be one of the important factors for hearth erosion. Viscosities of molten pig iron were precisely measured by the oscillating crucible method in Fig. 10, the effect of sulfur and titanium on the viscosity of molten pig iron was opposite. The viscosity of molten pig iron itself was relatively small, but the proportion of viscosity change from $[\mathrm{Ti}]=0.05 \%$ to [Ti] $=0.20 \%$ at $1723 \mathrm{~K}$ was $3.82 \%$ as a result of calculation. That was not so small. The viscosity of molten pig iron increased with the addition of titanium based on the mechanism that the radius of the titanium atom was larger than the iron, and the free moving space of the iron atom was reduced. However, the viscosity of molten pig iron decreased with the increase of sulfur content. The relationship between the viscosity and the surface tension of molten pig iron: ${ }^{27)}$

$$
\frac{\gamma}{\eta}=\frac{15}{16} \sqrt{\frac{k T}{m}}
$$

where $\gamma$ is the surface tension of molten pig iron, $\mathrm{N} \cdot \mathrm{m}^{-1} ; \eta$ is the viscosity of molten pig iron, $\mathrm{mPa} \cdot \mathrm{s} ; k$ is the Boltzmann constant; $T$ is the temperature, $\mathrm{K} ; m$ is the mass of the atom.

Thus, the viscosity and the surface tension of molten pig iron change in the same direction. Moreover, the low viscosity of molten pig iron containing sulfur promoted the mass transfer of carbon in molten pig iron, and the high viscosity of molten pig iron containing titanium restrained the mass transfer of carbon in molten pig iron which would be another factor resulting in different erosion of carbon brick.

\subsubsection{Kinetic Analysis}

From the viewpoint of kinetics, the dissolution rate of carbon brick can be expressed as Eq. (12) when the dissolution is controlled by the carbon diffusion in molten pig iron: ${ }^{28)}$

$$
n_{D}=\frac{\rho_{L} A}{1200} k_{D}\left(C_{s}-C_{b}\right)
$$

where $n_{D}$ is the dissolution rate, $\mathrm{mol} \cdot \mathrm{m}^{-2} \cdot \mathrm{s}^{-1} ; k_{D}$ is the mass transfer coefficient of carbon in molten pig iron, $\mathrm{m} \cdot \mathrm{s}^{-1}$;

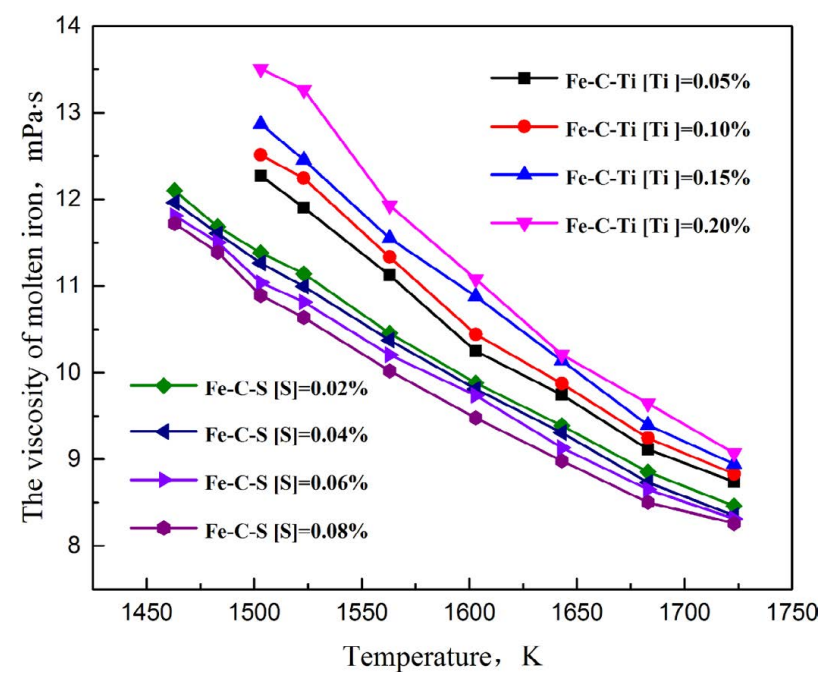

Fig. 10. Effects of sulfur and titanium on the viscosity. (Online version in color.)
Therefore, the dissolution rate will increase with the increase of mass transfer coefficient of carbon. The mass transfer coefficient of carbon is a function of several parameters $k_{D}=f(\mu, D, U, d)$, and different quasi numbers are employed to describe the relationship: ${ }^{3)}$

$$
\begin{aligned}
& S h S c^{-1 / 3}=5.46 \mathrm{Re}^{3.01} \\
& S h=\frac{k_{D} d}{D} . \\
& S c=\frac{\mu}{D} \\
& \operatorname{Re}=\frac{d U}{\mu}
\end{aligned}
$$

The mass transfer coefficient of carbon can be expressed from the above equations:

$$
\begin{gathered}
k_{D}=5.46 \frac{d^{2.01} U^{3.01} D^{0.67}}{\mu^{2.68}} \ldots \\
k_{D}=5.46 \frac{d^{2.01} U^{3.01} D^{0.67} \rho^{2.68}}{\eta^{2.68}}
\end{gathered}
$$

where $\mu$ is the kinematic viscosity of molten pig iron, $\mathrm{m}^{2} \cdot \mathrm{s}^{-1} ; \eta$ is the dynamic viscosity of molten pig iron, $\mathrm{mPa} \cdot \mathrm{s} ; D$ is the diffusion coefficient, $\mathrm{m}^{2} \cdot \mathrm{s}^{-1} ; U$ is the circumferential velocity of the cylinder, $\mathrm{m} \cdot \mathrm{s}^{-1} ; d$ is the diameter of carbon brick, m;

According to Eq. (18), mass transfer coefficient is proportional to -2.68 th power of viscosity. Assuming the difference of erosion rate by changing sulfur or titanium content is attributed to the difference of mass transfer coefficient, it is considered that the difference of erosion rate is also attributed to the difference of viscosity. Presuming the value of viscosity by extrapolation of curves in Fig. 10, the ratio of mass transfer coefficient by changing sulfur content could be expressed as the following equation:

$$
k_{D([S]=0.02)} / k_{D([S]=0.08)} \propto\left(\eta_{([S]=0.02)} / \eta_{([S]=0.08)}\right)^{-2.68} \ldots
$$

The result of the ratio of mass transfer coefficient will be compared with the ratio of erosion rate. The mass transfer coefficient of liquid metal with $[\mathrm{S}]=0.08 \%$ was calculated 1.07 times as much as that with $[\mathrm{S}]=0.02 \%$ at $1723 \mathrm{~K}$. The change of viscosity will cause the increase of mass transfer coefficient so that the erosion rate will increase. Meanwhile, the wetting angle between molten pig iron and carbon brick will decrease with the increase of sulfur content due to the effect of surface tension, the contact time of molten pig iron and new carbon brick will be shortened. The new ironcarbon interface will quickly be wetted by molten pig iron containing high sulfur content after a layer of carbon brick is dissolved. The continuous interfacial reaction will increase the erosion rate of carbon brick.

Therefore, the different influence of sulfur and titanium on the surface tension and viscosity of molten pig iron is the essential cause of the interaction. 


\section{Conclusions}

Effects of sulfur and titanium interaction in molten pig iron on erosion of carbon brick were investigated, the quantitative relationship between the erosion rate and sulfur and titanium interaction was obtained based on experimental data, the mechanism of sulfur and titanium interaction was analyzed. The following conclusions are obtained:

(1) The erosion of carbon brick was enhanced when the sulfur content increased separately in molten pig iron, however, this effect could be made up by the addition of titanium in molten pig iron.

(2) It is suggested that sulfur content in molten pig iron should be controlled less than $0.04 \%$ and titanium content in molten pig iron should be controlled more than $0.10 \%$ in actual production, when the $\mathrm{BF}$ at the end of the service.

(3) The quantitative relationship between the erosion rate and sulfur and titanium interaction at $1773 \mathrm{~K}$ was obtained based on experimental data, when sulfur content increased by $0.01 \%$, the increment of titanium content by $0.015 \%$ would be needed to compensate for the effect of sulfur content on the erosion.

(4) The erosion process of carbon brick was presumed, the iron-carbon interface is the key reason for the erosion. The different influence of sulfur and titanium on the surface tension and viscosity of molten pig iron is the essential cause of the interaction.

\section{Acknowledgments}

This work was financially supported by the National Natural Science Foundation of China (51874025), the National Science Foundation for Young Scientists of China (51704019), Major Science and Technology Program for Water Pollution Control and Treatment (2017ZX07402001), supported by the Fundamental Research Funds for the
Central Universities (FRF-BD-17-010A) and (FRF-TP-17040A1).

\section{REFERENCES}

1) K. X. Jiao, J. L. Zhang, Z. J. Liu, C. L. Chen and Y. X. Liu: ISIJ Int., 56 (2016), 1956

2) Y. Deng, J. L. Zhang and K. X. Jiao: Metall. Res. Technol., 114 (2017), 210

3) Y. Deng, J. L. Zhang and K. X. Jiao: ISIJ Int., 58 (2018), 815.

4) K. X. Jiao, J. L. Zhang, Q. F. Hou, Z. J. Liu and G. W. Wang: Steel Res. Int., 88 (2017), 1600475.

5) Y. Hino, H. Matsunaga and K. Watanabe: ISIJ Int., 57 (2017), 697.

6) Y. Z. Yuan: J. Iron Steel Res., 3 (1983), 529.

7) D. S. Vinoo, D. Mazumdar and S. S. Gupta: Ironmaking Steelmaking, 34 (2007), 471.

8) A. Kumar, Z. E. Chacko, M. Malathi, K. M. Godiwalla, S. K. Ajmani and S. Ranganathan: Steel Res. Int., 85 (2014), 927.

9) D. Lindstrom, P. Nortier and D. Sichen: Steel Res. Int., 85 (2014), 76.

10) M. Wen, T. A. Zhang and Z. Dou: ISIJ Int., 56 (2016), 103.

11) D. Lindström and S. Du: Metall. Mater. Trans. B, 46 (2015), 83.

12) J. H. Ji, R. Q. Liang and J. C. He: ISIJ Int., 56 (2016), 794.

13) Y. Nakai, Y. Hino, I. Sumi, N. Kikuchi, Y. Uchida and Y. Miki: ISIJ Int., 55 (2015), 1398.

14) M. Magnelöv, A. Carlsson-Dahlberg, L. Gustavsson, J. Björkvall and B. Björkman: Ironmaking Steelmaking, 42 (2015), 525.

15) S. J. Nam, Y. B. Kang, S. M. Jung and Y. Sasaki: ISIJ Int., 53 (2013), 1779.

16) J. L. Liao, J. Li, X. D. Wang and Z. T. Zang: Ironmaking Steelmaking, 39 (2012), 133.

17) Y. Li, Y. Q. Li and R. J. Fruehan: ISIJ Int., 41 (2001), 1417.

18) G. A. Swift and R. Koc: J. Mater. Sci., 34 (1999), 3083.

19) E. Park and O. Ostrovski: ISIJ Int., 44 (2004), 74.

$20)$ E. Park and O. Ostrovski: ISIJ Int., 43 (2003), 1316

21) Y. Deng, J. L. Zhang and K. X. Jiao: Iron Steel, 53 (2018), 25

22) J. Y. Zhang: Physical Chemistry of Metallurgy, Metallurgical Industry Press, Beijing, (2007), 318.

23) H. J. Guo: Physical Chemistry of Metallurgy, Metallurgical Industry Press, Beijing, (2006), 41.

24) Z. F. Yuan, J. J. Ke and J. Li: Surface Tension of Metal and Alloy, Science Press, Beijing, (2006), 1

25) J. X. Zhao and L. B. Li: Metallurgical Principle, Metallurgical Industry Press, Beijing, (2012), 88.

26) K. Mukai: ISIJ Int., 32 (1992), 19.

27) X. Y. Teng, G. H. Min, H. L. Liu, Z. Q. Shi, H. R. Wang and Y. F. Ye: Mater. Sci. Technol., 9 (2001), 383.

28) Y. Shigeno, M. Tokuda and M. Ohtani: J. Jpn. Inst. Met., 46 (1982), 713. 